\title{
A kinetic study of mercury(II) transport through a membrane assisted by new transport reagent
}

\author{
Mehmet Karakus ${ }^{1}$, Hamza Korkmaz Alpoguz ${ }^{1 *}$, Ahmet Kaya ${ }^{1}$, Nurcan Acar ${ }^{2}$, Ahmet Orhan Görgülü ${ }^{3}$ and \\ Mustafa Arslan 3,4
}

\begin{abstract}
Background: A new organodithiophosphorus derivative, namely O-(1,3-Bispiperidino-2-propyl)-4-methoxy phenyldithiophosphonate, was synthesized and then the kinetic behavior of the transport process as a function of concentration, temperature, stirring rate and solvents was investigated.

Results: The compound 1 was characterized by elemental analysis, IR, ${ }^{1} \mathrm{H}$ and ${ }^{31} \mathrm{P}$ NMR spectroscopies. The transport of mercury(II) ion by a zwitterionic dithiophosphonate $\mathbf{1}$ in the liquid membrane was studied and the kinetic behavior of the transport process as a function of concentration, temperature, stirring rate and solvents was investigated. The compound $\mathbf{1}$ is expected to serve as a model liquid membrane transport with mercury(II) ions.

Conclusion: A kinetic study of mercury(II) transport through a membrane assisted by O-(1,3-Bispiperidino-2-propyl)4-methoxy phenyldithiophosphonate was performed. It can be concluded that the compound $\mathbf{1}$ can be provided a general and straightforward route to remove toxic metals ions such as mercury(II) ion from water or other solution.
\end{abstract}

\section{Background}

Dithiophosphorus Derivatives have been a subject of intensive study due to having an important role in medicine, agricultural and industrial application fields in the last decades [1-15]. They have been utilized as additives in lubricant oils, solvent-extraction reagents for metals, and flotation agents for mineral ores, insecticides and pesticides [1-5]. While many dithiodiphosphonates and their derivatives such as thiophoshonyl disulfane have been synthesized by a ring opening reaction of Lawesson reagent's or its analogues and alcohols, zwitterionic dithiophosphonate and thiophoshonyl disulfane type compounds are rare. Dithiophosphonates can be oxidized to bis(thiophoshonyl)disulfane by $\mathrm{Cu}$ (II) ions or iodine [7]. Recently, a few researches have focused on the zwitterionic dithiophosphonates [6]. Dithiophosphonates can be oxidized to bis(thiophoshonyl)disulfane by $\mathrm{Cu}$ (II) ions or iodine [7]

In this paper, we reported the synthesis of O-(1,3-Bispiperidino-2-propyl)-4-methoxy phenyldithiophosphonate and the kinetic behavior of the transport process as

\footnotetext{
* Correspondence: hkalpoguz@pau.edu.tr

'Department of Chemistry, Faculty of Arts and Sciences, Pamukkale University, 20017, Denizli, Turkey

Full list of author information is available at the end of the article
}

a function of concentration, temperature, stirring rate and solvents was also investigated. The compound $\mathbf{1}$ was characterized by elemental analysis, IR and ${ }^{1} \mathrm{H}$ NMR and ${ }^{31}$ P- NMR spectroscopies.

\section{Results and discussion}

The reaction of 2,4-bis(4-methoxyphenyl)-1,3,2,4-dithiadiphosphetane-2,4-disulfide with 1,3-bispiperidino-2propanol gave rise to the formation 1 which was previously synthesized (Scheme 1) [16]. The spectroscopic data of the compound $\mathbf{1}$ was remained. The compound was obtained in high yield and was characterized by elemental analysis, IR, ${ }^{1} \mathrm{H}$-NMR and ${ }^{31} \mathrm{P}-\mathrm{NMR}$ spectroscopies. Although dithiophosphonates were usually obtained as liquid product, the compound $\mathbf{1}$ was obtained as solid product due to zwitterionic character in which the $\mathrm{H}$ atom of the initially formed $\mathrm{P}-\mathrm{SH}$ group transferred to the piperidino group. The IR spectra of $\mathbf{1}$ showed its characteristic bands at $671 \mathrm{~cm}^{-1}$ for $\mathrm{n}(\mathrm{PS})$ asym and $548 \mathrm{~cm}^{-1}$ for $\mathrm{n}(\mathrm{PS})_{\text {sym }}$ stretchings.

The ${ }^{1} \mathrm{H}$-NMR spectra of $\mathbf{1}$ indicated that the phenyl protons displayed doublet at 8.13-8.08 $\mathrm{ppm}\left({ }^{3} \mathrm{~J}_{\mathrm{PH}}=\right.$ $\left.14.19 \mathrm{~Hz}, \mathrm{~J}_{\mathrm{HH}}=8.81 \mathrm{~Hz}\right)$ and $6.90-6.87 \mathrm{ppm}\left({ }^{4} \mathrm{~J}_{\mathrm{PH}}=\right.$ $2.45 \mathrm{~Hz}, \mathrm{~J}_{\mathrm{H}, \mathrm{H}}=8.81 \mathrm{~Hz}$ ), respectively. The spectra showed the expected signals for piperidino and 


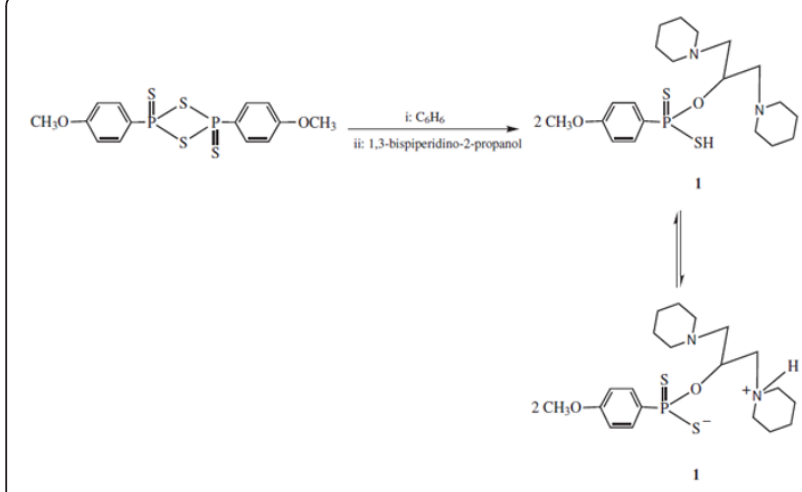

Scheme 1 Synthesis of the carrier 1

methylene protons. However, the proton on $\mathrm{N}$ atom was not observed in the spectra of ${ }^{1} \mathrm{H}$ NMR. The ${ }^{31} \mathrm{P}-\mathrm{NMR}$ spectra of 1 displayed a quartet at 112.73 ppm because of the coupling with hydrogen nuclei and the presence of two isomer in solution(see scheme 1).

\section{Transport studies}

In our previous report [16], the transport of $\mathrm{Cu}$ (II) ions from aqueous phase was carried out by using the compound $\mathbf{1}$ as the carrier. In this work, the transport of mercury(II) ion by the zwitterionic dithiophosphonate $\mathbf{1}$ in the liquid membrane was studied and the kinetic behavior of the transport process as a function of concentration, temperature, stirring rate and solvents was investigated.

The mechanism of the ion pair mediated transport (co-transport) is given in Figure 1. L represents the carrier $\mathbf{1}$. At the interface between donor and membrane, metal picrate ion pair forms complex with ligand, then the $[\mathrm{LM}]^{+} \mathrm{Pic}^{-}$complex diffuses through the membrane. At the interface between membrane and acceptor, the carrier ion pairs are decomplexed and $\mathrm{M}^{+} \mathrm{Pic}^{-}$is liberated into the acceptor phase. Finally, the ligand carrier diffuses back across the membrane aqueous boundary

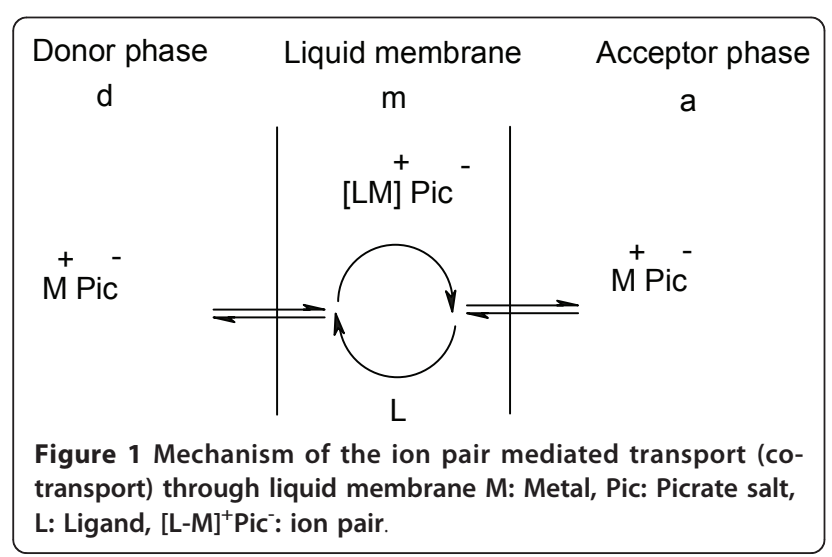

layers. The variation of the metal picrate concentration with time was directly measured in both the donor $\left(C_{d}\right)$ and acceptor $\left(\mathrm{C}_{\mathrm{a}}\right)$ phases. In the experiments, the variation of picrate ion concentration with time was directly measured in both donor $\left(C_{d}\right)$ and acceptor phases $\left(C_{a}\right)$. The corresponding change of picrate ion concentration in the membrane phase was determined from the material balance between the phases.

For practical reasons, the dimensionless reduced concentrations were used:

$$
R_{d}=\frac{C_{d}}{C_{d 0}} \quad R_{m}=\frac{C_{m}}{C_{d 0}} \quad R_{a}=\frac{C_{a}}{C_{d 0}}
$$

where $C_{d 0}$ is the initial mercury(II) ion concentration in the donor phase, while $C_{d}, C_{m}$ and $C_{a}$ represents the mercury(II) ion concentration in donor, membrane and acceptor phases, respectively. The material balance with respect to the reduced concentrations can be expressed as $R_{d}+R_{m}+R_{a}=1$. From this expression, the kinetic behavior of the consecutive irreversible first order reactions can be described as follows;

$$
C_{d} \stackrel{k_{1}}{\rightarrow} C_{m} \stackrel{k_{2}}{\rightarrow} C_{a}
$$

where $\mathrm{k}_{1}$ and $\mathrm{k}_{2}$ are the apparent membrane entrance and exit rate constants, respectively. The kinetic scheme for consecutive reaction systems and the kinetic parameters of $k_{1}$ and $k_{2}$ from the obtained data were calculated by fitting equations as described in the previous studies [17-24].

The variation of the reduced concentration of mercury (II) ion through the liquid membrane with $1 \times 10^{-4} \mathrm{M}$ of carrier 1 in $\mathrm{CHCl}_{3}$ at $300 \mathrm{rpm}$ and $25^{\circ} \mathrm{C}$ is presented in Figure 2. The observed experimental results reveal that $R_{d}$ decreases exponentially with time, accompanied by a

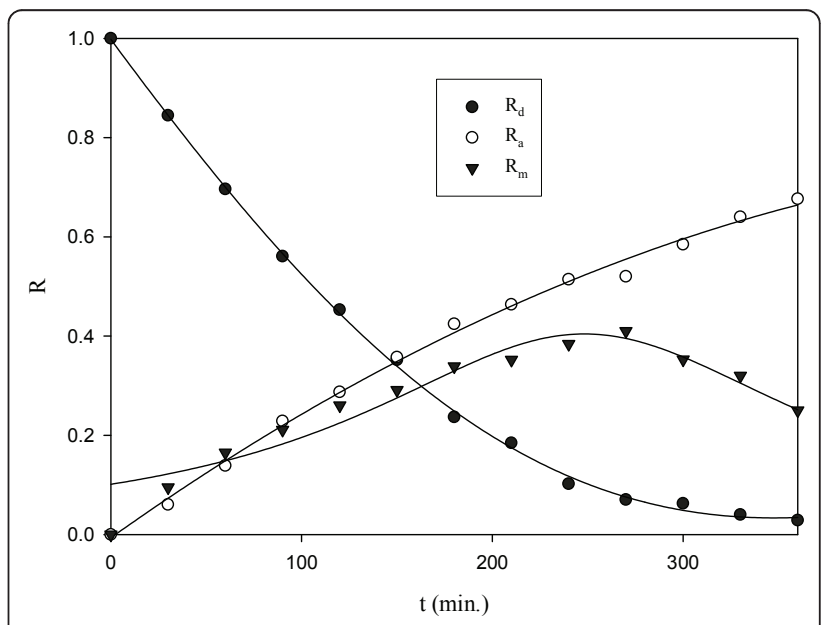

Figure 2 Time dependence of $R_{d}, R_{m}$, and $R_{a}$ for transport of mercury(II). Membrane: $1 \times 10^{-4} \mathbf{M}$ of carrier $\mathbf{1}$ in $\mathrm{CHCl}_{3}$ (298 K and 300 rpm). 
simultaneous increase of $R_{a}$, whereas $R_{m}$ presents a maximum at intermediate times.

\section{Effect of Carrier Concentration in Membrane on Transport of Mercury(II) lons}

The transport experiments were carried out at three different initial carrier 1 concentrations $1 \times 10^{-6}, 1 \times 10^{-5}$, and $1 \times 10^{-4} \mathrm{M}$ in $\mathrm{CHCl}_{3}$ at $298 \mathrm{~K}$ and $300 \mathrm{rpm}$. The obtained kinetic parameters for the effect of concentration of carrier $\mathbf{1}$ are presented in Table 1. It was found that the initial carrier concentration influences the kinetic constants, as well as flux values and the results are in full agreement with previously obtained results [17-24]. It can be seen that both kinetic constants $k_{1}$ and $k_{2}$ or fluxes are dependent on the carrier concentration and increases steadily with the initial carrier concentration as shown in Figure 3. In addition, a blank experiment was performed with no present carrier in the membrane. There was no evidence of the movement of the mercury(II) ions through the liquid membrane in the blank experiment. When the carrier was utilized, the transport of mercury(II) ions through the liquid membrane was performed.

Effect of Temperature on Transport of Mercury(II) Ions

The effect of temperature on the transport of mercury (II) ions through the liquid membrane containing $1 \times$ $10^{-4} \mathrm{M}$ of carrier 1 in $\mathrm{CHCl}_{3}$ was examined at 293, 298, 303 , and $308 \mathrm{~K}(300 \mathrm{rpm})$. The experimental results are collected in Table 2 . It is quite obvious that $k_{1}$ and $k_{2}$ increases with an increase in the temperature. Table 2 also shows that $t_{\max }$ and $R_{m}{ }^{\max }$ decreases with an increase of temperature.

The activation energy was calculated from plot of the maximum membrane exit flux $\left(\mathrm{J}_{\mathrm{a}}{ }^{\mathrm{max}}\right)$ versus $(1 / \mathrm{T})$ at $300 \mathrm{rpm}$ (Equation 3), as presented in Figure 4.

$$
\ln (J)=\ln (A)-\frac{E_{a}}{R}\left(\frac{1}{T}\right)
$$

The activation energy value for carrier $\mathbf{1}$ in the liquid membrane was found to be $1.36 \mathrm{kcal} / \mathrm{mol}$ by using the equation 3. As known, activation energy values are quite low for diffusion-controlled processes, whose rate constants are strongly affected by temperature [25]. It was pointed out that the activation energies of diffusion-controlled processes are lower than $10 \mathrm{kcal} / \mathrm{mol}$ [25]. The

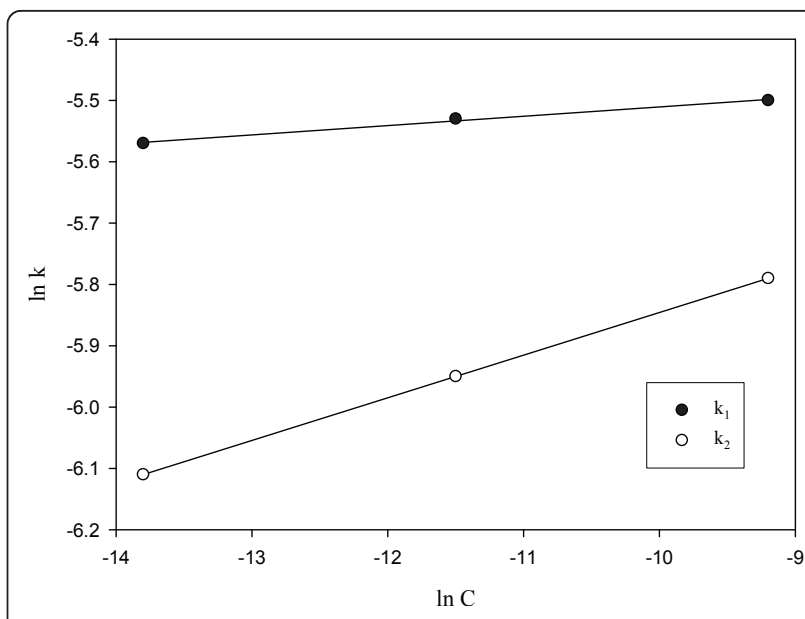

Figure 3 Concentration dependence of $k_{1}$ and $k_{2}$ for transport of mercury(II) with 1 (298 K and $300 \mathrm{rpm}$ in $\mathrm{CHCl}_{3}$ ).

calculated activation energy for carrier 1 shows that the transport of mercury(II) ion is diffusion-controlled processes.

\section{Effect of Stirring Rate on Transport of Mercury(II) lons}

To achieve effective mercury(II) transport, it is necessary to explore the effect of stirring speed on the transport process. In the present investigation, the stirring rate of the membrane phase was carried out at three different stirring rate, 200, 300, and $400 \mathrm{rpm}$ at $298 \mathrm{~K}$ when the carrier 1 concentration was $1 \times 10^{-4} \mathrm{M}$ in $\mathrm{CHCl}_{3}$. The results are given in Table 3 and indicate that the stirring rate affects the transport rate of mercury(II) through the liquid membrane. According to these results, the flux increases with increasing stirring rate due to decrease of the thickness of the diffusion boundary layers at both interfaces of the membrane.

\section{Effect of Solvent on Transport of Mercury(II) lons}

The present work was to investigate the physicochemical approach to co-transport of mercury(II) transport through a liquid membrane containing carrier $\mathbf{1}$. Therefore, the effect of solvents on the transport process was studied under the same conditions, and the results obtained with $\mathrm{CH}_{2} \mathrm{Cl}_{2}$ and $\mathrm{CCl}_{4}$ are presented in Table 4, along with analogous results for $\mathrm{CHCl}_{3}$. It has been observed that the membrane entrance and exit rate constants are found to vary in the order

Table 1 The kinetic parameters for mercury(II) ions at different carrier 1 concentrations in $\mathrm{CHCl}_{3}$ (298 $\mathrm{K}$ and $300 \mathrm{rpm}$ )

\begin{tabular}{|c|c|c|c|c|c|c|c|}
\hline $\begin{array}{l}\text { Concentration } \\
\text { (M) }\end{array}$ & $\begin{array}{l}\mathrm{k}_{1} \times 10^{3} \\
\left(\mathrm{~min}^{-1}\right)\end{array}$ & $\begin{array}{l}\mathrm{k}_{2} \times 10^{3} \\
\left(\mathrm{~min}^{-1}\right)\end{array}$ & $\mathrm{R}_{\mathrm{m}}^{\max }$ & $\begin{array}{l}\mathbf{t}_{\max } \\
(\min )\end{array}$ & $\begin{array}{l}J_{d}^{\max } \times 10^{3} \\
\left(\min ^{-1}\right)\end{array}$ & $\begin{array}{l}\mathrm{J}_{\mathrm{a}}^{\max } \times 10^{3} \\
\left(\min ^{-1}\right)\end{array}$ & $\%$ Transport \\
\hline $1 \times 10^{-6}$ & 3.81 & 2.21 & 0.47 & 340.17 & -1.04 & 1.04 & 57.56 \\
\hline $1 \times 10^{-5}$ & 3.95 & 2.61 & 0.45 & 309.39 & -1.16 & 1.16 & 58.96 \\
\hline $1 \times 10^{-4}$ & 4.10 & 3.07 & 0.42 & 280.79 & -1.29 & 1.29 & 67.64 \\
\hline
\end{tabular}


Table 2 The kinetic parameters of mercury(II) transport using carrier 1 at different temperatures (Stirring rate is 300 rpm; solvent is $\mathrm{CHCl}_{3}$ )

\begin{tabular}{|c|c|c|c|c|c|c|c|}
\hline $\begin{array}{l}\text { Temperature } \\
\text { (K) }\end{array}$ & $\begin{array}{l}k_{1} \times 10^{3} \\
\left(\min ^{-1}\right)\end{array}$ & $\begin{array}{l}k_{2} \times 10^{3} \\
\left(\min ^{-1}\right)\end{array}$ & $\mathrm{R}_{\mathrm{m}}^{\max }$ & $\begin{array}{l}t_{\max } \\
(\min )\end{array}$ & $\begin{array}{l}J_{d}^{\max } \times 10^{3} \\
\left(\min ^{-1}\right)\end{array}$ & $\begin{array}{l}\mathrm{J}_{\mathrm{a}}^{\max } \times 10^{3} \\
\left(\min ^{-1}\right)\end{array}$ & $\%$ Transport \\
\hline 293 & 4.03 & 2.02 & 0.50 & 343.45 & -1.26 & 1.26 & 52.80 \\
\hline 298 & 4.10 & 3.07 & 0.42 & 280.79 & -1.29 & 1.29 & 67.64 \\
\hline 303 & 4.18 & 3.20 & 0.41 & 272.88 & -1.34 & 1.34 & 70.16 \\
\hline 308 & 4.25 & 3.47 & 0.40 & 260.01 & -1.41 & 1.41 & 73.52 \\
\hline
\end{tabular}

$\mathrm{CH}_{2} \mathrm{Cl}_{2}>\mathrm{CHCl}_{3}>\mathrm{CCl}_{4}$, and the variation of $\mathrm{R}_{\mathrm{a}}$ values is illustrated in Figure 5 . This shows that the $R_{a}$ values are strongly affected by the membrane solvent system, and the higher transport efficiency was observed with $\mathrm{CH}_{2} \mathrm{Cl}_{2}$ solvent. The efficiency of $\mathrm{CH}_{2} \mathrm{Cl}_{2}$ with respect to the $\mathrm{R}_{\mathrm{a}}$ values was higher than of $\mathrm{CHCl}_{3}$ and $\mathrm{CCl}_{4}$, because their viscosity values were in the reverse order.

The physicochemical properties of the solvents are given in Table 5. These observations suggest that viscosity is playing a major role in ion transport as well as the polarity. Thus, we have shown that the nature of the membrane solvent is one of the main factors in establishing transport efficiency.

\section{Conclusion}

A kinetic study of mercury(II) transport through a membrane assisted by O-(1,3-Bispiperidino-2-propyl)4-methoxy phenyldithiophosphonate was performed. The kinetic behavior of the transport process as a function of concentration, temperature, stirring rate and solvents was investigated. It can be concluded that dithiophosphorus derivatives can be provided a general and straightforward route to remove toxic metals ions such as mercury(II) ion from water or other solution.

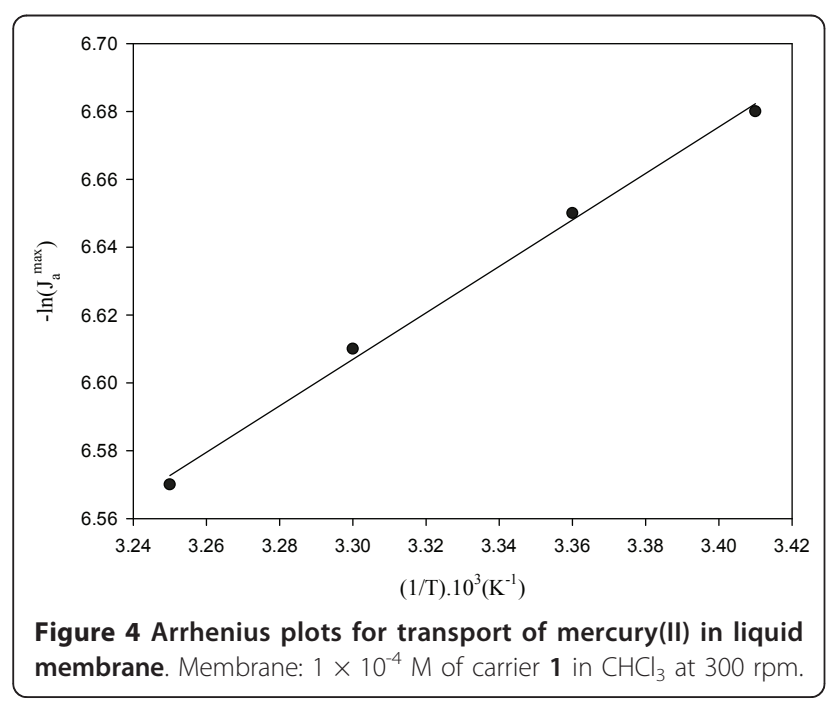

\section{Experimental}

Solvents were purchased from Merck and distilled before use. 2,4-bis(4-methoxyphenyl)-1,3,2,4-dithiadiphosphetane-2,4-disulfide (Lawesson's reagent) were obtained from Aldrich. 1,3-Bispiperidino-2-propanol was synthesized by the methods given in the literature [26]. ${ }^{1} \mathrm{H}$-NMR spectra were obtained in chloroform with a Bruker-DPX 400 FTNMR spectrometer. IR spectra was recorded on a Mattson 1000 FTIR spectrometer using $\mathrm{KBr}$ pellets in the range of $4000-400 \mathrm{~cm}^{-1}$. Melting points were determined with a Gallenkamp apparatus without uncorrected.

\section{Liquid Membrane Transport Experiments}

The chemical reagents used in these experiments were mercury(II) nitrate, dichloromethane, chloroform, carbon tetracholoride and picric acid obtained from Merck. Mercury(II) picrate solution was prepared by the addition of a $1 \times 10^{-2} \mathrm{M}$ mercury(II) nitrate to a $2.5 \times 10^{-5}$ $\mathrm{M}$ aqueous picric acid solution and shaken at $25^{\circ} \mathrm{C}$ for 1 hour. The aqueous solutions were prepared using demineralised water.

\section{Kinetic Procedure}

Mercury(II) ion transport experiments were conducted using a thermostated (Grand mark, model W14, Grants Instruments, Cambridge, England) apparatus. Transport experiments were carried out in a U-type cell (Figure 6). An organic solution $(20 \mathrm{~mL})$ containing the carrier 1 was placed in the bottom of the cell and two portions of aqueous donor and acceptor solutions $(10 \mathrm{~mL})$ were carefully added on top of them. Both surface areas were $2.5 \mathrm{~cm}^{2}$. The organic phase was stirred at variable speeds magnetically (Chiltern mark, model HS 31). The initial phases consisted of the donor phase, an aqueous mercury(II) picrate $\left(2.5 \times 10^{-5} \mathrm{M}\right)$ solution, while the membrane phase was made up by dissolving carrier 1 $\left(\mathrm{C}_{\text {carrier }}=10^{-4} \mathrm{M}\right)$ in the organic phase. The acceptor phase consisted of doubly distilled water. Samples were taken from both water phases (acceptor and donor phases) at various intervals of time and the picrate ion concentration was analyzed by a spectrophotometric method [27]. The spectrophotometric measurements were performed by an UV-Vis Spectrometer Shimadzu 
Table 3 The kinetic parameters of mercury(II) transport using carrier 1 at different stirring rates (T = $298 \mathrm{~K}$; solvent is $\mathrm{CHCl}_{3}$ )

\begin{tabular}{|c|c|c|c|c|c|c|c|}
\hline $\begin{array}{l}\text { Stirring Rate } \\
\text { (rpm) }\end{array}$ & $\begin{array}{l}k_{1} \times 10^{3} \\
\left(\min ^{-1}\right)\end{array}$ & $\begin{array}{l}k_{2} \times 10^{3} \\
\left(\min ^{-1}\right)\end{array}$ & $\mathrm{R}_{\mathrm{m}}^{\max }$ & $\begin{array}{l}t_{\mathrm{ax}} \\
(\mathrm{min})\end{array}$ & $\begin{array}{l}\mathrm{J}_{\mathrm{d}}^{\max } \times 10^{3} \\
\left(\min ^{-1}\right)\end{array}$ & $\begin{array}{l}J_{a}^{\max } \times 10^{3} \\
\left(\min ^{-1}\right)\end{array}$ & $\%$ Transport \\
\hline 200 & 4.03 & 1.08 & 0.62 & 446.37 & -0.67 & 0.67 & 30.12 \\
\hline 300 & 4.10 & 3.07 & 0.42 & 280.79 & -1.29 & 1.29 & 67.64 \\
\hline 400 & 4.33 & 4.91 & 0.35 & 220.98 & -1.69 & 1.69 & 70.72 \\
\hline
\end{tabular}

Table 4 The kinetic parameters for mercury(II) transport using carrier 1 when different solvents are used (298 K and $300 \mathrm{rpm}$ )

\begin{tabular}{|c|c|c|c|c|c|c|c|}
\hline Solvent & $\begin{array}{l}k_{1} \times 10^{3} \\
\left(\min ^{-1}\right)\end{array}$ & $\begin{array}{l}k_{2} \times 10^{3} \\
\left(\min ^{-1}\right)\end{array}$ & $\mathrm{R}_{\mathrm{m}}^{\max }$ & $\begin{array}{l}t_{\max } \\
(\min )\end{array}$ & $\begin{array}{l}J_{d}^{\max } \times 10^{3} \\
\left(\min ^{-1}\right)\end{array}$ & $\begin{array}{l}J_{a}^{\max } \times 10^{3} \\
\left(\min ^{-1}\right)\end{array}$ & $\%$ Transport \\
\hline $\mathrm{CH}_{2} \mathrm{Cl}_{2}$ & 4.51 & 6.12 & 0.31 & 189.61 & -1.92 & 1.92 & 89.72 \\
\hline $\mathrm{CHCl}_{3}$ & 4.10 & 3.07 & 0.42 & 280.79 & -1.29 & 1.29 & 67.64 \\
\hline $\mathrm{CCl}_{4}$ & 3.49 & 0.41 & 0.75 & 694.86 & -0.31 & 0.31 & 16.64 \\
\hline
\end{tabular}

160A. Each experimental result reported is the arithmetic mean of two independent measurements.

\section{0 - (1,3-Bispiperidino-2-propyl) - 4-}

methoxyphenyldithiophosphonate (1)

2,4-Bis (methoxyphenyl-1,3,2,4- dithiadiphosphetane-2,4disulfide (Lawesson's reagent) (0.89 g, $2.21 \mathrm{mmol}$ ) was reacted with 1,3-bispiperidino-2-propanol (1 g, 4.42 $\mathrm{mmol}$ ) in benzene $(5 \mathrm{~mL})$. The mixture was refluxed for 20-30 minutes. The product was obtained as orange solid. The orange solid was filtered, dried in air and recrystallised from $\mathrm{CHCl}_{3}$. The yield is $1.35 \mathrm{~g}(72 \%)$ and $\mathrm{mp}: 178-180^{\circ} \mathrm{C}$. Elemental Analysis Calc. for $\mathrm{C}_{20} \mathrm{H}_{33} \mathrm{~N}_{2} \mathrm{O}_{2} \mathrm{PS}_{2}$ : C, 56.04; H, 7.76; N, 6.53; S, 14.96. Found: C, 55.80; H, 7.52; N, 6.0; S, 14.58. IR $\left(\mathrm{cm}^{-1}\right)$ : $1035 \mathrm{n}(\mathrm{P}-\mathrm{O}-\mathrm{C}), 671 \mathrm{n}(\mathrm{PS}), 548 \mathrm{n}(\mathrm{PS}) .{ }^{1} \mathrm{H}-\mathrm{NMR}\left(\mathrm{CDCl}_{3}\right)$,

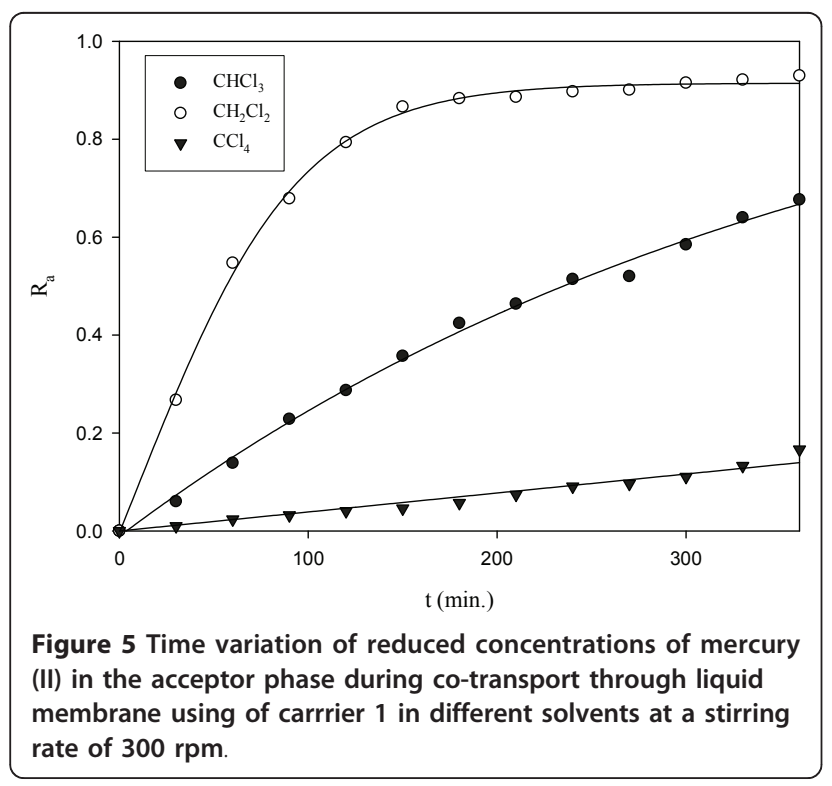

d: $8.13-8.08\left(\mathrm{dd}, 2 \mathrm{H},{ }^{3} \mathrm{~J}_{\mathrm{PH}}=14.19 \mathrm{~Hz}, \mathrm{~J}_{\mathrm{HH}}=8.81 \mathrm{~Hz}\right)$, 6.90-6.87 (dd, $\left.2 \mathrm{H},{ }^{4} \mathrm{~J}_{\mathrm{PH}}=2.45 \mathrm{~Hz}, \mathrm{~J}_{\mathrm{HH}}=8.81 \mathrm{~Hz}\right), 5.36-$ $5.30(\mathrm{~m}, 1 \mathrm{H}, \mathrm{OCH}), 3.81$ (s, $\left.3 \mathrm{H}, \mathrm{OCH}_{3}\right), 3.03-2.99$ (m, $8 \mathrm{H}$, orto protons to $\mathrm{N}$ on the piperidino ring), 2.91$2.86(\mathrm{~m}, 4 \mathrm{H}$, bridge methylene $\mathrm{H}), 1.82-1.77(\mathrm{~m}, 8 \mathrm{H}$, meta protons to $\mathrm{N}$ on the piperidino ring), 1.56-1.53 (m, $4 \mathrm{H}$, para protons to $\mathrm{N}$ on the piperidino ring). ${ }^{31} \mathrm{P}$ $\operatorname{NMR}\left(\mathrm{CDCl}_{3}\right)$, d: 112.73 ( $\mathrm{q}$, due to the coupling with hydrogen nuclei and the presence of two isomer in solution)(see scheme 1).

\section{Table 5 Physicochemical characteristic of solvents used}

\begin{tabular}{cccc}
\hline Physicochemical Properties & $\mathrm{CH}_{\mathbf{2}} \mathrm{Cl}_{\mathbf{2}}$ & $\mathrm{CHCl}_{\mathbf{3}}$ & $\mathbf{C C l}_{\mathbf{4}}$ \\
\hline$\varepsilon_{0}$ & 9.08 & 4.81 & 2.24 \\
$\mathrm{n}_{\mathrm{D}}$ & 1.424 & 1.446 & 1.466 \\
$\mu$ & 1.959 & 1.354 & 0 \\
$\eta$ & 0.437 & 0.58 & 0.969 \\
$V_{m}$ & 64.2 & 96.5 & 96.5 \\
\hline
\end{tabular}

$\varepsilon_{0}$ : dielectric constant $\left(20^{\circ} \mathrm{C}\right) ; \mathrm{n}_{\mathrm{D}}$ : refractive index $\left(20^{\circ} \mathrm{C}\right) ; \mu$ : dipole moment (D); $\eta$ : viscosity $(\mathrm{CP}) ; \mathrm{Vm}$ : molar volume $\left(\mathrm{M}^{-1}\right)$.

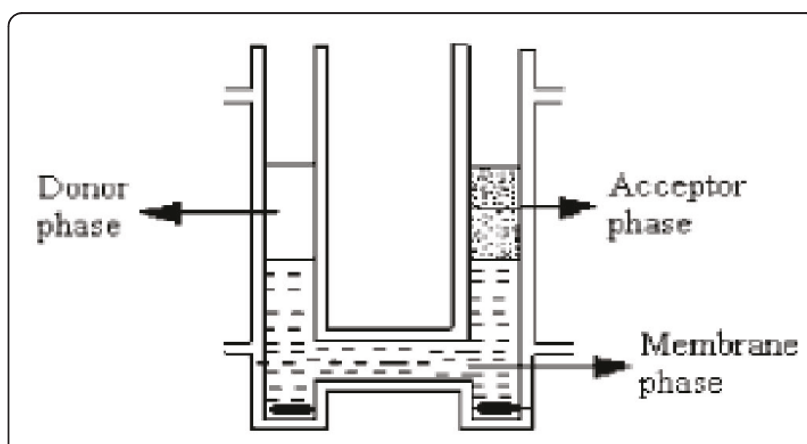

Figure 6 Bulk liquid membrane apparatus for transport of mercury(II) ions; $d$, donor phase; $a$, acceptor phase; $m$, membrane phase. 


\section{Acknowledgements}

This work was supported by TUBITAK Grant No: TBAG-HD/123 (106T034).

\section{Author details}

'Department of Chemistry, Faculty of Arts and Sciences, Pamukkale University, 20017, Denizli, Turkey. ${ }^{2}$ Department of Chemistry, Faculty of Science, Ankara University, Tandogan, 06100, Ankara, Turkey. ${ }^{3}$ Department of Chemistry, Faculty of Arts and Sciences, Firat University, 23169, Elazig, Turkey. ${ }^{4}$ Yildiz Technical University, Education Faculty, Istanbul-Turkiye.

\section{Authors' contributions}

MK has coordinated the study and characterization of the compound $\mathbf{1}$. NA carried out the synthesis of the compound 1. HKA and AK carried out the kinetic studies and participated in the design of the study. AOG and MA carried ot the synthesis of the starting metarials. All authors have read and approved the final manuscript.

\section{Competing interests}

The authors declare that they have no competing interests.

Received: 1 April 2011 Accepted: 15 July 2011 Published: 15 July 2011

\section{References}

1. Aragoni MC, Arca M, Demartin F, Devillanova FA, Graiff A, Isaia F, Lippolis V, Tripicchio A, Verani G: Reactivity of phosphonodithioato Ni-II complexes: solution equilibria, solid state studies and theoretical calculations on the adduct formation with some pyridine derivatives. J Chem Soc Dalton Trans 2001, 18:2671-2677.

2. Gray IP, Slawin AMZ, Woollins JD: Synthesis and structure of $\left[\mathrm{An}(\mathrm{RO}) \mathrm{PS}_{2}\right]^{]}$ complexes. Dalton Trans 2004, 16:2477-2486.

3. Gray IP, Slawin AMZ, Woollins JD: Synthesis and characterization of disulfides and esters derived from their sodium organodithiophosphonate salts. New J Chem 2004, 28:1383-1389.

4. Thomas $C M$, Neels $A$, Stoeckli-Evans $H$, Süss-Fink $G$ : Synthesis and structure Of $\left[\left(\mathrm{C}_{5} \mathrm{H}_{5}\right) \mathrm{Fe}\left(\mathrm{C}_{5} \mathrm{H}_{5}\right) \mathrm{Fe}\left(\mathrm{C}_{5} \mathrm{H}_{4} \mathrm{PS}_{2} \mathrm{OCH}_{2} \mathrm{C}_{6} \mathrm{H}_{4} \mathrm{~N}_{3}\right)^{-}\right.$, a new phosphonodithioate derivative, and its coordination chemistry with rhodium(I) and nickel(II). J Organomet Chem 2001, 633:85-90.

5. Karakus $M$, Sahin M, Bilgic S: An investigation on the inhibition effects of some new dithiophosphonic acid monoesthers on the corrosion of the steel in $1 \mathrm{M} \mathrm{HCl}$ medium. Mater Chem Phys 2005, 92:565-571.

6. Karakus M, Aydogdu Y, Celik O, Kuzucu V, Ide S, Hey-Hawkins E: Synthesis, molecular structure, optical properties and electrical conductivity of zwitterionic ferrocenyldithiophosphonates. Z Anorg Allg Chem 2007, 633:405-410.

7. Haiduc I, Goh LY: Reactions of bis(thiophosphoryl)disulfanes and bis (thiophosphinyl)disulfanes with metal species: an alternative, convenient route to metal complex and organometallic dithiophosphates and dithiophosphinates. Coord Chem Rev 2002, 224:151-170.

8. Haiduc I, Sowerby DB, Lu SF: Stereochemical aspects of phosphor-1,1dithiolato metal complexes (dithiophosphates, dithiophosphinates): Coordination patterns, molecular structures and supramolecular associations-l. Polyhedron 1995, 14:3389-3472.

9. Haiduc I: Thiophosphorus and related ligands in coordination, organometallic and supramolecular chemistry. A personal account. J Organomet Chem 2001, 623:29-42.

10. Bromberg L, Lewin I, Warshawsky A: Membrane extraction of mercury (II) and silver (I) by bis(di(2 ethylhexyloxy)thiophosphoryl)disulfide. Hydrometallurgy 1993, 33:59-71.

11. Van Zyl WE, Fackler JP: A general and convenient route to dithiophosphonate salt derivatives. Phosphorus, Sulfur, Silicon and Relat Elem 2000, 167:117-132.

12. Van Zyl WE, Staples RJ, Fackler JP: Dinuclear gold(I) dithiophosphonate complexes: formation, structure and reactivity. Inorg Chem Commun 1998, 1:51-54.

13. Van Zyl WE: Dithiophosphonates and related P/S-type ligands of group 11 metals. Comments Inorg Chem 2010, 31:13-45.

14. Van der Walt $H$, Muller A, Van Zyl WE: Triethylammonium o-3ß-cholest-5en-3-yl(4-methoxyphenyl)-dithiophosphonate. Acta Cryst 2010, , E66: 2146-2147.
15. Barranco EM, Crespo O, Gimeno MC, Jones PG, Laguna A: Unprecedented formation of novel phosphonodithioate ligands from diferrocenyldithiadiphosphetane disulfide. Inorg Chem 2008, 47:6913-6918.

16. Alpoguz HK, Kaya A, Karakus M: Mechanism and kinetics of copper(II) transport through a liquid membrane containing a dithiophosphonate derivative as carrier. Turk J of Chem 2005, 29:345-353.

17. Minhas FT, Solangi IB, Memon S, Bhanger Ml: Kinetic study of Pb(II) transport through a bulk liquid membrane containing calix[6]arene hexaester derivative as carrier. Sep Sci Tech 2010, 45:1448-1455.

18. Minhas FT, Memon $\mathrm{S}$, Bhanger MI: Transport of $\mathrm{Hg}(\mathrm{II})$ through bulk liquid membrane containing calix[4]arene thioalkyl derivative as a carrier. Desalination 2010, 262:215-220.

19. Alpoguz HK, Memon S, Ersoz M, Yilmaz M: Transport of $\mathrm{Hg} 2+$ through bulk liquid membrane using a bis-calix[4]arene nitrile derivative as carrier: kinetic analysis. New J Chem 2002, 26:477-480.

20. Yllmaz A, Kaya A, Alpoguz HK, Ersoz M, Yilmaz M: Kinetic analysis of chromium(VI) ions transport through a bulk liquid membrane containing p-tert-butylcalix[4]arene dioxaoctylamide derivative. Sep Purif Technol 2008, 59:1-8.

21. Szpakowska M, Naggy OB: Chemical kinetic approach to the mechanism of coupled transport of $\mathrm{Cu}(\mathrm{II})$ ions through bulk liquid membranes. J Phys Chem A 1999, 103:1553-1559.

22. Granado-Castro MD, Galindo-Riano MD, Dominguez-Lledo FC, GarciaVargas M: Study of the kinetics of the transport of $\mathrm{Cu}(\mathrm{II}), \mathrm{Cd}(\mathrm{II})$ and $\mathrm{Ni}(\mathrm{II})$ ions through a liquid membrane. Anal Bioanal Chem 2008, 391:779-788.

23. Szpakowska M: Kinetics of coupled transport of $\mathrm{Cu}(\mathrm{II})$ ions through liquid membranes composed of technical solvents and paraffin mixtures. $J$ Membr Sci 1994, 92:267-273.

24. Szpakowska M, Naggy OB: Nonsteady state vs steady- state kineticanalysis of coupled ion-transport through binary-liquid membranes. $J$ Membr Sci 1993, 76:27-38.

25. Lazarova Z, Boyadzhiev L: Kinetic aspects of copper(II) transport across liquid membrane containing Lix-860 as a carrier. J Membr Sci 1993, 78:239-245.

26. Yakuphanoglu F, Gorgulu AO, Aydogdu Y, Aydogdu A, Arslan M: The synthesis, characterization, and electrical conductivity of the potassium salt of 1,3-dipiperidin-1-ylpropan-2-O-xanthate. Synth React Inorg Met-Org Chem 2003, 33:911-923.

27. Deligoz H, Yilmaz M: Liquid- liquid -extraction of transition-metal cations by calixarene based cyclic ligands. Solvent Extr Ion Exch 1995, 13:19-26.

doi:10.1186/1752-153X-5-43

Cite this article as: Karakus et al: A kinetic study of mercury(II) transport through a membrane assisted by new transport reagent. Chemistry Central Journal 2011 5:43.

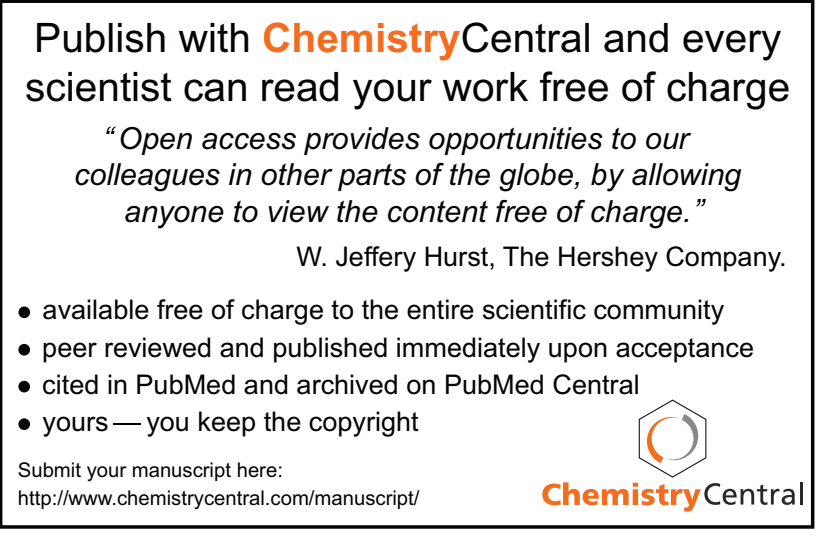

